\title{
Prólogo \\ Hacia la construcción de un nuevo paradigma social
}

\author{
David Barkin \\ Universidad Autónoma Metropolitana - CampusXochimilco, Ciudad de México, México. \\ Email: barkin@correo.xoc.uam.mx
}

\section{Antonio Elizalde Hevia}

Polis. Revista Latinoamericana, Santiago, Chile. Email: antonio.elizalde@revistapolis.cl

Existe un creciente consenso en el mundo académico respecto a que el paradigma que ha inspirado el surgimiento del mundo moderno enfrenta una profunda crisis. Muestra de ello son la imposibilidad hasta ahora de dar cuenta de problemas endémicos de la humanidad que la modernidad ofreció resolver: guerra y violencia (fraternidad); pobreza e inequidad social (igualdad); y opresión (libertad). Más aún, los progresivos estragos sociales y ambientales de la sociedad mercado-céntrica señalan la necesidad de virar hacia formas alternativas de organización social y económica con más urgencia que nunca.

De manera similar, en la vida académica e intelectual es imprescindible proponer nuevos paradigmas que trasciendan las disciplinas que han evolucionado para respaldar el sistema actual, con su énfasis en el individualismo, la transformación de la naturaleza y las relaciones sociales en mercancías, la subyugación de todo al mercado y la centralidad de la propiedad privada.

Hay muchas búsquedas iniciadas para encontrar estos nuevos caminos. Resulta paradójico constatar que una creciente corriente de intelectuales viene sosteniendo que es en las prácticas ancestrales de las comunidades campesinas e indígenas, así como en sus formas actuales de organización y comportamiento, donde se hallan algunos principios para la construcción de otras sociedades.

Es interesante constatar asimismo que esas pistas posibles de seguir se encuentran también entre los paradigmas heterodoxos de las ciencias sociales. Muchos de ellos largamente depreciados y desvalorados desde el pensamiento hegemónico, pero que a la luz de recientes hallazgos en ámbitos tales como la neurofisiología, en una relectura de las teorías evolutivas o en la dinámica de sistemas, comienzan a ser revalorados. Analizar e incorporar estos enfoques a un conjunto teórico es la labor de los intelectuales comprometidos con las víctimas del sistema y con la consecución de un mundo mejor. 
Este número de Polis ofrece un espacio de reflexión crítica sobre los avances más significativos en paradigmas alternativos a los dominantes en la academia en nuestros países. Las contribuciones examinan críticamente la posibilidad de integrar estos avances en una nueva formulación que estamos tratando de elaborar en el marco de la Economía Ecológica, informada con la Economía Social y Solidaria. Esta convocatoria está motivada por nuestro convencimiento que el pensamiento crítico actual coadyuva a la construcción de ese nuevo paradigma social. Esta monografía ofrece una oportunidad de avanzar en la integración de este conjunto paradigmático y teórico para informar la construcción de estos otros mundos. La convocatoria original identificó nueve preguntas fundamentales para considerar, preguntas derivadas de un coloquio convocado por el Departamento de Producción Económica en el plantel Xochimilco de la Universidad Autónoma Metropolitana en la Ciudad de México.

Las preguntas planteadas fueron las siguientes:

\section{¿Crisis múltiples del sistema capitalista?}

A inicios del siglo XXI, el capitalismo mundial prosigue su marcha destructiva sobre los dos fundamentos de la riqueza de las naciones: el ser humano y la naturaleza. Pero no sólo genera contingentes cada vez más grandes de personas excluidas y exacerba el daño ambiental. Los problemas de deuda soberana y recurrentes convulsiones en el sector financiero son quizá el último estertor de una crisis de reproducción del propio sistema capitalista global. La confluencia de estas crisis multi-sistémicas es un primer tema posible.

\section{¿Entropía y los límites del crecimiento?}

El calentamiento global, la destrucción de ecosistemas, el agotamiento del petróleo y los riesgos en el uso de la energía nuclear, entre una larga lista de problemas ambientales, son prueba contundente de la vigencia de las formulaciones tempranas de los pensadores en el siglo XIX y su puesta al día por Georgescu-Roegen en los años setenta del siglo pasado sobre el carácter entrópico del proceso económico. Desde entonces viene siendo patente la imposibilidad de seguir con la dinámica del crecimiento inherente en las estructuras de las instituciones hegemónicas en el sistema mundial que actualmente impera. De cara al mainstream de las ciencias sociales, que domina el pensamiento filosófico académico en América Latina hoy, el análisis de sus formulaciones es imprescindible para la construcción de alternativas sostenibles.

\section{¿Aporías de la sustentabilidad capitalista?}

Si la idea del crecimiento sostenido de las economías capitalistas es de por sí cuestionable, ante los consustanciales movimientos cíclicos y recurrentes crisis; la pretensión académica y política de que tal crecimiento sea sostenible desde el punto de vista ambiental se constituye como uno de 
los más importantes mitos del sistema. Ir más allá del crecimiento como motor de una economía alternativa es otro núcleo temático.

\section{¿Son compatibles progreso tecnológico y calidad de vida?}

Actualmente, domina una idea de progreso en el que se presupone una sociedad de creciente consumo y desigualdades. Se supone una continuada progresión de innovaciones técnicas que ofrecen reducir el costo del consumo y la necesidad de insumos materiales (desmaterialización) para librar a la población y posibilitar así mayores actividades de realización personal y convivialidad. Es necesario explorar estos supuestos, junto con una evaluación del impacto del cambio tecnológico sobre los requerimientos de recursos y la liberación del tiempo para actividades sociales. Se contempla extender la reflexión a otros dominios, como la agroecología, que se ofrecen como respuestas a las crisis provocadas por el modelo actual de organizar la sociedad.

\section{¿El Buen vivir: Bolivia, Ecuador y otras propuestas regionales?}

Como parte de un proceso regional de distanciamiento de la lógica del mercado, los gobiernos de Ecuador y Bolivia han dado un paso adelante al anteponer y elevar a rango constitucional la ancestral concepción del Sumak Kawsay. No es el capital sino el ser humano y la naturaleza los que constituyen el centro de esta cosmovisión. Retroalimentar la discusión con estas prácticas alternativas es fundamental en aras de la construcción del nuevo paradigma social. Se pretende examinar el debate en torno a estas propuestas y los intentos que se llevan a cabo para materializarlas en distintos ámbitos institucionales.

\section{¿Resiliencia social?}

La capacidad social para recuperarse de choques externos (como desastres naturales) o de ajustarse a los cambios previstos (como el cambio climático) así como las previsiones respecto a las transformaciones en la política pública nacional e internacional presentan retos enormes para los pueblos comprometidos con construir sus propias estrategias socio-políticas, culturales y ambientales. Para los demás grupos sociales, dependientes de las previsiones de las políticas nacionales e internacionales, las posibilidades de ajuste son aún menores. ¿Cuáles son las lecciones que podríamos extraer de nuestras proyecciones para el futuro y la capacidad social para reaccionar de una manera constructiva?

\section{¿Convivencialidad?}

Iván Illich generalizó el uso de este término con base en su trabajo hace casi medio siglo, y es parte de varias líneas de pensamiento que surgieron a mediados del siglo pasado, incluyendo el uso por Castoriadis de la noción de autonomía; se observa una decidida relación e importancia del concepto con el problema de escala ("lo pequeño es hermoso") y las pro- 
puestas para construir otras sociedades (otros mundos posibles). Las exploraciones y propuestas de Illich ofrecen visiones de sociedades más compatibles con los imperativos de un equilibrio planetario y social.

\section{¿Ética de la vida y retorno del sujeto?}

A la economía de mercado le corresponde una ética funcional, a saber, una ética instrumental y utilitarista. Se trata de la ética del mercado. A una economía poscapitalista le es imprescindible una ética acorde a sus aspiraciones. La ética de la vida y la teoría del Sujeto desarrolladas por Dussel y Hinkelammert son piezas claves no sólo para la construcción del nuevo paradigma social, sino concepciones necesarias para que la vida humana sea posible.

\section{¿Autonomía y principios de otro mundo posible?}

El cuerpo de la teoría tradicional de las ciencias sociales y el análisis económico obran al servicio de la realidad vigente. El racionalismo matemático y el positivismo, insertos en una metodología individualista, construyen los marcos epistemológicos desde los cuales estos paradigmas han pretendido negar la posibilidad del cambio social. La filosofía política crítica, en cambio, defiende la idea de que la dinámica de la sociedad humana no obedece a leyes eternas. La inclusión de este horizonte de reflexión en el debate de otro mundo posible debe ser un objeto central de discusión. Las aportaciones de los diversos grupos sociales involucrados en sus propias estrategias para forjar una autonomía propia es reflejo de la realización social de la urgencia de esta labor.

Los trece ensayos incluidos en la sección "Lente de Aproximación” reúnen algunas de las reflexiones más sobresalientes del Coloquio que abordó el pensamiento en torno a la construcción de estos paradigmas, a los cuales se suman algunos trabajos enviados en respuesta a la convocatoria realizada. Hay una gran complementariedad entre ellos, partiendo de su crítica de la parcialidad o sesgos de la visión dominante, fincada en un modelo unidimensional del funcionamiento de nuestras sociedades en el cual la influencia del mercado ha sumergido la influencia de los demás facetas de nuestras vidas y la complejidad de la interacción entre la sociedad y el planeta de que dependemos, es decir, el metabolismo social. Es evidente, tras la lectura de estas contribuciones, que la humanidad cuenta con los recursos sociales y materiales para detener la destrucción ambiental y atender a las graves carencias sociales generadas por la organización actual del proceso productivo; asimismo, es evidente que la suma de los movimientos sociales tienen las capacidades creativas requeridas para implementar los cambios requeridos.

Sin embargo, es igualmente obvio que los cambios requeridos atañen a movimientos sociales que tendrían que derrocar a poderosos grupos sociales que han fabricado la ilusión de que los procesos de democracia representativa y de intercambio mercantil son adecuados para lograr un 
bienestar universal y atender a los desequilibrios que nuestros autores describen como de enorme gravedad. Para librarnos de las amenazas a las cuales nuestros colaboradores aluden claramente, habrá necesidad de mucho más que discusiones políticas y movilizaciones masivas; los múltiples movimientos locales y regionales están explorando los medios requeridos para una coordinación efectiva de sus acciones particulares, como estamos viendo en las diversas manifestaciones de los “occupy" en los países más ricos del mundo y en otros hermanados, como los "\#Yo Soy 132" que surgió en México como repudio del control monopolista de los medios durante las elecciones presidenciales de 2012.

Consideramos que la colección de ensayos reunidos en este Lente de Aproximación sigue con la tradición de Polis de ofrecer una mirada crítica al estado de conocimiento actual sobre las cuestiones sociales más candentes y aporta hacia una profundización del debate en torno a la definición de las rutas a caminar para detener el deterioro en la calidad de nuestras vidas y el planeta.

El número continúa con la sección Proyectos y Avances de Investigación que incluye el artículo de Gardy Augusto Bolívar Espinoza y Oscar Rogelio Caloca Osorio el trabajo titulado "Capital social y humano en convergencia. Asentamientos irregulares de Milpa Alta"; de Diego Checa Hidalgo, "El poder protector de la noviolencia. Defensores de derechos humanos e intervenciones internacionales noviolentas"; de Baldomero Estrada Turra, "Tecnología y modernización: evolución del transporte urbano en Valparaíso. 1850 - 1950"; de Noelia Figueroa Burdiles, "El desarrollo y las políticas públicas"; de Claudio Esteban Merino Jara, "Cultura, poder y rol de los intelectuales: El dilema de la batalla en el campo"; de Mauricio Ramírez Pérez Sau-Lyn Lee Maturana, "Factores asociados a la satisfacción vital en adultos mayores de $\mathbf{6 0}$ años”; de María Emilia Tijoux, Marisol Facuse y Miguel Urrutia el artículo que lleva por título "El Hip Hop: ¿Arte popular de lo cotidiano o resistencia táctica a la marginación? “; y la sección cierra con el trabajo de Marco A. Vega titulado “Aspectos y avances en ciencia, tecnología e innovación"

Finalmente la sección de Reseñas y Comentarios de Libros presenta la reseña escrita por Aitana Alguacil Denche del libro ¿ $\boldsymbol{Y}$ ahora qué? Impactos y resistencia social frente a la embestida ultraliberal, de varios autores; la de Fidel García Gutiérrez, quien reseña el libro Teoría y política de la educación. Reflexiones para el proceso formativo de María Jesús Vitón de Antonio; el de María Teresa Pozzoli, reseñando "Sin visiones nos perdemos”. Reflexiones sobre Teología Ecofeminista Latinoamericana de Maria Judith Ress; luego Andrea Precht Gandarillas e Ilich Silva-Peña realizan un comentario del documental La Educación Prohibida. Nuevos paradigmas educativos en América Latina de Germán Doin; y finalmente la reseña realizada por Jorge Riquelme Rivera sobre el libro Sesenta años de la CEPAL. Textos seleccionados del decenio 1998-2008 de Ricardo Bielschowski (compilador). 